\title{
Knowledge, attitudes, risk perception of influenza and influenza vaccination among final year nursing students in Singapore: an exploratory study
}

R Leong

From 3rd International Conference on Prevention and Infection Control (ICPIC 2015)

Geneva, Switzerland. 16-19 June 2015

\section{Introduction}

In Singapore, Influenza causes about 600 deaths (out of $15,000)$ affecting people who are over 65 years old ('Ministry of Health: FAQs', 2014). Influenza vaccination benefits health-care workers (HCWs) and reduces influenza-related morbidity and mortality in high-risk patients. However, only $25 \%$ of student nurses have reported having received seasonal or $\mathrm{H} 1 \mathrm{~N} 1$ vaccination [1].

\section{Objectives}

To explore the relationship among final year nursing students' knowledge, risk perception, health beliefs and their influenza vaccination behaviours and uptake in Singapore.

\section{Study design}

This study utilised a non-experimental, cross-sectional exploratory quantitative study design.

\section{Methods}

Convenience sampling was used to recruit 868 final year nursing students in Singapore from October 2013 to January 2014. Two survey forms were used to collect data: (i) Participants' Demographic Information sheet and (ii) King's Nurses Influenza Vaccination Questionnaire (KNIVQ).

\section{Results}

Student nurses' vaccination rates were $15.7 \%$ for Seasonal Influenza vaccine and 5.4\% for Influenza A (H1N1) vaccine. Findings revealed a relationship between vaccination uptake rates and knowledge and risk perception and student nurses' perceived health locus of control $(\mathrm{p}<0.05)$.
The results also described the different level of student nurses' vaccination behaviours and their vaccination recommendation to patients. Vaccinated student nurses were also more likely to recommend the Influenza vaccine to their patients in the future.

\section{Conclusion}

The findings provide valuable input enabling policy makers develop measures to improve influenza vaccination awareness and take-up rates among students, encouraging them to be patient advocates regarding importance of influenza vaccination for health prevention and promotion.

\section{Disclosure of interest}

None declared.

Published: 16 June 2015

References

1. Hunt C, Arthur A: Student nurses' reasons behind the decision to receive or decline influenza vaccine: a cross-sectional survey. Vaccine 2012, 30(40):5824-5829.

2. Zhang J, While AE, Norman IJ: Nurses' knowledge and risk perception towards seasonal influenza and vaccination and their vaccination behaviours: a cross-sectional survey. Int J Nurs Stud 2011, 48(10):1281-1289.

\section{doi:10.1186/2047-2994-4-S1-P19}

Cite this article as: Leong: Knowledge, attitudes, risk perception of influenza and influenza vaccination among final year nursing students in Singapore: an exploratory study. Antimicrobial Resistance and Infection Control 2015 4(Suppl 1):P19. 